\title{
Poeciliopsis Lucida Hepatocellular
}

\section{Carcinoma}

National Cancer Institute

\section{Source}

National Cancer Institute. Poeciliopsis Lucida Hepatocellular Carcinoma. NCI Thesaurus.

Code C134962.

Hepatocellular carcinoma that occurs in Poeciliopsis lucida. 